\title{
Immunogenicity of varicella zoster virus glycoprotein $E$ DNA vaccine
}

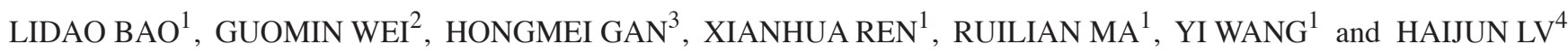 \\ ${ }^{1}$ Department of Pharmacy, Affiliated Hospital of Inner Mongolia Medical University, Hohhot, Inner Mongolia 010059; \\ Departments of ${ }^{2}$ Respiratory and ${ }^{3}$ Intensive Care Unit, Binzhou People's Hospital, Binzhou, Shandong 256610; \\ ${ }^{4}$ Department of Scientific Research, Affiliated Hospital of Inner Mongolia Medical University, \\ Hohhot, Inner Mongolia 010059, P.R. China
}

Received November 13, 2014; Accepted October 27, 2015

DOI: $10.3892 / \mathrm{etm} .2016 .3086$

\begin{abstract}
In the present study a eukaryotic expression vector of varicella zoster virus (VZV) glycoprotein $\mathrm{E}(\mathrm{gE})$ was constructed and enabled to express in COS7 cells. Furthermore, a specific immune response against the VZV gE eukaryotic expression plasmid was induced in BALB/c mice. The VZV gE gene was amplified using polymerase chain reaction (PCR) and cloned into a eukaryotic expression vector, pcDNA3.1. The recombinant vector was subsequently transfected into COS7 cells using a liposome transfection reagent. The recombinant protein was instantaneously expressed by the transfected cells, as detected by immunohistochemistry, and the recombinant pcDNA-VZV gE plasmid was subsequently used to immunize mice. Tissue expression levels were analyzed by reverse transcription-PCR. In addition, the levels of serum antibodies and spleen lymphocyte proliferation activity were investigated. The amplified target gene included the full-length gE gene $(\sim 2.7 \mathrm{~kb})$, and the recombinant expression vector induced $\mathrm{gE}$ expression in COS7 cells. In addition, the expression plasmid induced sustained expression in vivo following immunization of mice. Furthermore, the plasmid was capable of inducing specific antibody production and effectively stimulating $\mathrm{T}$ cell proliferation. Effective humoral and cellular immunity was triggered in the mice immunized with the VZV gE eukaryotic expression vector. The results of the present study laid the foundation for future research into a VZV DNA vaccine.
\end{abstract}

Correspondence to: Professor Haijun Lv, Department of Scientific Research, Affiliated Hospital of Inner Mongolia Medical University, 1 Northern Tongdao Street, Hohhot, Inner Mongolia 010059, P.R. China

E-mail: 1vhaijundsr@163.com

Key words: varicella zoster virus, glycoprotein E, vaccine, immunogenicity

\section{Introduction}

Determination of a target gene is the crucial initial step in DNA vaccine research. In recent years, researchers around the world have screened protective antigens of varicella zoster virus (VZV), exploring a series of antigen markers with various degrees of immune protective effects (1). Previous studies have demonstrated that the glycoprotein $\mathrm{E}(\mathrm{gE})$ antigen is one of the most promising candidate antigen markers $(2,3)$. $\mathrm{gE}$ is one of the most important protective antigens in $\mathrm{VZV}$, and since it is capable of inducing cellular and humoral immunity, $\mathrm{gE}$ is considered the most appropriate candidate antigen for a DNA vaccine (4).

Various eukaryotic proteins exhibit very low biological activity when synthesized in bacteria, due to incorrect folding or low folding efficiency (5). When using a cloned gene, post-translational processing, including disulfide bond formation, glycosylation and phosphorylation, is often required to produce eukaryotic proteins with true biological activity (6). However, post-translational processing cannot be conducted in prokaryotic cells; therefore, mammalian cell expression vectors are often required to express the secreted protein with the desired biological function. By inducing the corresponding gene into eukaryotic cells, proteins with high bioactivities may be expressed (7).

Previous studies have demonstrated that corresponding protein antigens may be successfully expressed following DNA vaccine administration, and these protein antigens are capable of simulating a natural infection and producing a more comprehensive immune response $(8,9)$. The antigen-specific cellular and humoral immune responses must be detected following administration of a DNA vaccine directed against a pathogenic microorganism or malignant tumor, in order to evaluate the immune effects of the DNA vaccine. Furthermore, it is helpful to elucidate the detailed mechanism underlying how a DNA vaccine induces cellular and humoral immune responses in an organism. The results obtained may provide a crucial experimental basis for the development of novel and highly efficient DNA vaccines against pathogenic microorganisms or malignant tumors $(10,11)$.

pcDNA-VZV gE is a eukaryotic expression plasmid of VZV gE that was constructed in the present study, and 
was used as a DNA vaccine to immunize BALB/c mice via intramuscular injection. The specific antibody levels, spleen lymphocyte proliferation activity and specific cytotoxic $\mathrm{T}$ lymphocyte (CTL) responses were analyzed in the mice, and compared with those of mice immunized with the pcDNA3.1 plasmid. The results obtained laid the foundation for future research into a VZV DNA vaccine.

\section{Materials and methods}

Materials. Specific pathogen-free BALB/c female mice, aged 4-6 weeks old and weighing 18-20 g were purchased from Shanghai SLAC Laboratory Animal Co., Ltd. (Shanghai, China). The pcDNA3.1 plasmid, recombinant COS7 cell lines (kidney fibroblasts transformed by SV40 viral genes) were purchased from Amresco, LLC (Solon, OH, USA); whereas Taq DNA polymerase, T4 DNA ligase, TRIzol ${ }^{\circledR}$ (Invitrogen) and various restriction endonucleases were purchased from Thermo Fisher Scientific, Inc. (Waltham, MA, USA). Liposome, VZV gE monoclonal antibodies (ab52549; Abcam, Cambridge, UK) and VZV gE were purchased from Shanghai Baoman Biological Technology Co., Ltd. (Shanghai, China); methylthiazolyltetrazolium (MTT) was purchased from Beijing Bole Life Science Development Co., Ltd. (Beijing, China); a two-step reverse transcription-polymerase chain reaction (RT-PCR) kit was purchased from Shanghai Sunred Biological Technology Co., Ltd. (Shanghai, China); horseradish peroxidase (HRP)-labeled goat anti-mouse immunoglobulin (Ig)G (E030110-02; EarthOx, Millbrae, CA, USA) was purchased from Sigma-Aldrich (St. Louis, MO, USA); an ultraviolet spectrophotometer (Ci6x; X-Rite, Inc., Grand Rapids, MI, USA). The gel imaging system was purchased from GE Healthcare Bio-Sciences (Pittsburgh, PA, USA), the microcentrifuge was purchased from Beijing Jingli Centrifuge Co. Ltd. (Beijing, China). The study was approved by the ethics committee of Inner Mongolia Medical University (Hohhot, China).

Primer design. Primer sequences were designed using Primer 5.0 design software (Premier Biosoft, Palo Alto, CA, USA), according to the previously published VZV gE DNA sequence (7). The upstream primer was introduced with a BamHI restriction site (underlined sequence), as follows: 5'-TCCAGAATGGCGCTTATACTC-3'; whereas the downstream primer was introduced with a termination codon and XbaI restriction site (12) (underlined sequence), as follows: 5'-TTCCACCAGGTCTAATCTATTCCT-3'. Primers used to amplify the VZV gE gene were synthesized by Shanghai Jiang Lai Biotechnology Co., Ltd. (Shanghai, China).

Double digestion of recombinant plasmid. Double digestion was initiated by adding $15 \mu \mathrm{l}$ recombinant plasmid DNA into a $1.5 \mathrm{ml}$ centrifuge tube, recombinant plasmid according to previously described methods (13). The double digestion reaction system included: $9 \mu \mathrm{lddH} 2 \mathrm{O} ; 1.5 \mu \mathrm{l} \mathrm{BamHI}$ (1 U/ $\mu \mathrm{l}) ; 1.5 \mu \mathrm{l} \mathrm{XbaI}(1 \mathrm{U} / \mu \mathrm{l}) ; 3 \mu \mathrm{l}$ buffer; and $15 \mu \mathrm{l}$ recombinant plasmid (20 $\mu \mathrm{l}$ was prepared in total), incubated at $37^{\circ} \mathrm{C}$ for $3 \mathrm{~h}$. Following double digestion, $10 \mu \mathrm{l}$ reaction mixture was used to detect the digestion effect using $1 \%$ agarose gel electrophoresis.
Detection of expression product using immunohistochemistry. Confluent COS7 cells, transfected with recombinant plasmid pcDNA-VZV gE, were fixed with cold acetone and washed three times with phosphate-buffered saline (PBS) for $5 \mathrm{~min}$. Plasmid transfection was conducted according to previously described methods (14). Immunohistochemical detection was conducted in a conventional manner. The process was conducted as follows, the cover glass was sealed at room temperature for $30 \mathrm{~min}$ using sealing liquid, following which, anti-VZV gE monoclonal mouse antibody (1:50) was added and incubated at $37^{\circ} \mathrm{C}$ overnight prior to washing three times with PBS for 5 min. Biotin-labeled goat anti-mouse IgG (1:100) was added to the cover glass, inoculated at $37^{\circ} \mathrm{C}$ for $30 \mathrm{~min}$ and washed with PBS for $5 \mathrm{~min}$, three times. Subsequently, HRP-labeled streptavidin (1:100; Luwen, Wuhan, China) was added, incubated at $37^{\circ} \mathrm{C}$ for $30 \mathrm{~min}$ and washed three times with PBS for $5 \mathrm{~min}$. Finally, the cover glass was stained using diaminobenzidine (DAB) color buffer. Following observation under a microscope (Olympus, Tokyo, Japan), the cover glass was washed with tap water to terminate the reaction and subsequently re-stained. Untransfected COS7 cells and COS7 cells transfected with the pcDNA3.1 null vector were used as negative controls.

Immunization of mice with plasmid DNA. A total of $30 \mathrm{BALB} / \mathrm{c}$ female mice aged 4-6 weeks old were randomly divided into three groups: i) Negative control group injected with null vector pcDNA3.1; ii) control group injected with sterile saline; and iii) experimental group injected with recombinant pcDNA-VZV gE ( $\mathrm{n}=10$ per group). Immunization was performed as follows, the inner thigh hairs of the mice were sheared off and the mice were grouped according to the sites marked by picric acid. The quadriceps femoris injection sites were pretreated with 50-100 $\mu$ l bupivacaine hydrochloride $(5 \mathrm{ml} / \mathrm{l}) 24 \mathrm{~h}$ prior to injection. Each reagent was injected to the same site via multi-point injection. The inoculation amount was $100 \mu \mathrm{g} / 100 \mu \mathrm{l} / \mathrm{mouse}$ and immunity was boosted every 2 weeks, three times in total.

Sample collection and preparation. A total of 2 weeks after the final immunization, $60 \mathrm{mg}$ quadriceps femoris tissue samples were harvested from the mice, rinsed three times with PBS and treated with diethylpyrocarbonate (DEPC). Subsequently, the quadriceps femoris sections were cut into $1-\mathrm{mm}^{2}$ sections, placed in a DEPC-treated homogenate tube, treated with $1 \mathrm{ml} \mathrm{TRIzol}{ }^{\circledR}$ reagent and homogenized into a uniform suspension in an ice bath. Subsequently, the homogenate was transferred into a DEPC-treated 1.5-ml centrifuge tube and incubated at room temperature for $10 \mathrm{~min}$ prior to centrifugation at $5,000 \mathrm{x} \mathrm{g}$ for $15 \mathrm{~min}$ at $4^{\circ} \mathrm{C}$. The supernatant was subsequently discarded and the precipitate was washed with $75 \%$ ethanol and vortexed. The precipitate and ethanol solution was centrifuged at $5,000 \mathrm{x}$ g for $5 \mathrm{~min}$ at $4^{\circ} \mathrm{C}$. The supernatant was discarded, the precipitate was re-washed using $75 \%$ ethanol and centrifuged again as above. Subsequently, the supernatant was discarded and the precipitate was naturally dried at room temperature and dissolved using $50 \mu 1$ DEPC-processed Tris EDTA buffer. The concentration of the solution was measured using a nucleic acid protein analyzer (Nano-200; HEBk, Xi'an, China) and adjusted to $0.5 \mu \mathrm{g}$. The solution was subsequently 
stored at $-20^{\circ} \mathrm{C}$ prior to RT-PCR amplification using specific primers.

RT-PCR analysis. Total RNA from cultures was extracted using TRIzol, followed by DNase treatment using the DNA-Free RNA Kit (Zymo Research Corporation, Irvine, CA, USA) according to manufacturer's instruction. The total RNA concentration and purity were determined using UV spectrophotometry at 260 and $280 \mathrm{~nm}$. cDNA was prepared using the SuperScriptIII First-Strand Synthesis System (Invitrogen; Thermo Fisher Scientific, Inc.) to reverse transcribe $1 \mu 1$ total RNA. RT-PCR was performed on the ViiA 7 Real-Time PCR System (Applied Biosystems; Thermo Fisher Scientific, Inc.). Primer template DNA sequences: VZV gE forward, 5'-ATG GATCCTATGGGGACAGTTAA-3' and reverse: 5'-TCT CTAGATCACCGGGTCTTATCTAT-3'. Primer sequences for glyceraldehyde 3-phosphate dehydrogenase (GAPDH) are described elsewhere (15). A 20- $\mu 1$ reaction system was constructed, composed of the following: $2 \mu 1$ 10X Taq Buffer (100 mM Tris $\mathrm{HCl}$ and $500 \mathrm{mM} \mathrm{KCl}) ; 2 \mu 1 \mathrm{MgCl}_{2}(25 \mathrm{mM})$; $2 \mu 1 \mathrm{dNTPs}(100 \mathrm{mM}) 2 \mu 1 ; 0.5 \mu 1$ each forward and reverse primers $(10 \mathrm{pM}) ; 1 \mu \mathrm{l}$ DNA template $(\sim 100 \mathrm{ng}) ; 0.2 \mu 1 \mathrm{Taq}$ DNA polymerase (5 $\mathrm{U} / \mu 1)$; and nuclease-free water made the total volume up to $20 \mu \mathrm{l}$. The reaction system was incubated in a thermalcycler, according to the following protocol: Initial denaturation, $94^{\circ} \mathrm{C}$ for $4 \mathrm{~min} ; 30$ cycles of denaturation at $94^{\circ} \mathrm{C}$ for $30 \mathrm{sec}$, annealing at $55^{\circ} \mathrm{C}$ for $30 \mathrm{sec}$ and extension at $72^{\circ} \mathrm{C}$ for $45 \mathrm{sec}$; and a final extension, $72^{\circ} \mathrm{C}$ for $5 \mathrm{~min}$. Two negative controls were used in the PCR: i) The minus-RT control from the previous step; and ii) a minus-template PCR. A BJS gel image analysis system (Shanghai Qiaofeng Industrial Co., Ltd., Shanghai, China) was used to scan the band density, and the results were normalized against GAPDH.

Detection of specific antibodies in mice. On days 7, 21 and 35 following the final immunization, blood samples were taken from the eyeballs of three mice (Procaine injection anesthesia; Disha Pharm Co., $1 \% / 2 \mathrm{ml}$ ) from each group and were placed at $4{ }^{\circ} \mathrm{C}$ overnight in order to collect the serum, by subjecting whole blood to centrifugation at 5,000 $\mathrm{x}$ g for $15 \mathrm{~min}$. The enzyme-linked immunosorbent assay (ELISA; Bio-Tek, Winooski, VT, USA) plate was placed in a pure grade S ELISA plate reader (BrandTech Scientific, Inc., Essex, CT, USA) and the OD value of the serum samples was determined at $450 \mathrm{~nm}$. The samples were deemed positive for the antibody if: Mean OD450 of sample $>$ mean OD450 $\mathrm{nm}$ of control +3 times of standard deviation (SD). The highest dilution of the serum sample that demonstrated a positive reaction was regarded as the antibody titer (16).

Detection of spleen T lymphocyte subgroups. On day 21 following mice immunization, a $0.6-\mathrm{ml}$ suspension of spleen lymphocytes was harvested, centrifuged at 5,000 $\mathrm{xg}$ for $5 \mathrm{~min}$, washed twice with $1 \mathrm{ml}$ fluorescence lotion (Nanjing SenBeijia Biotechnology Co., Ltd., Nanjing, China) and equally divided into two aliquots. The two aliquots were supplemented with $50 \mu 1$ fluorescein isothiocyanate-marked anti-mouse $\mathrm{CD}^{+}$(ab187745; Abcam, Cambridge, UK) and $50 \mu 1$ phycoerythrin-labeled anti-mouse $\mathrm{CD}^{+}$(ab4055; Abcam) monoclonal antibodies, respectively, and incubated at room temperature for $15 \mathrm{~min}$ in the dark. Subsequently, the

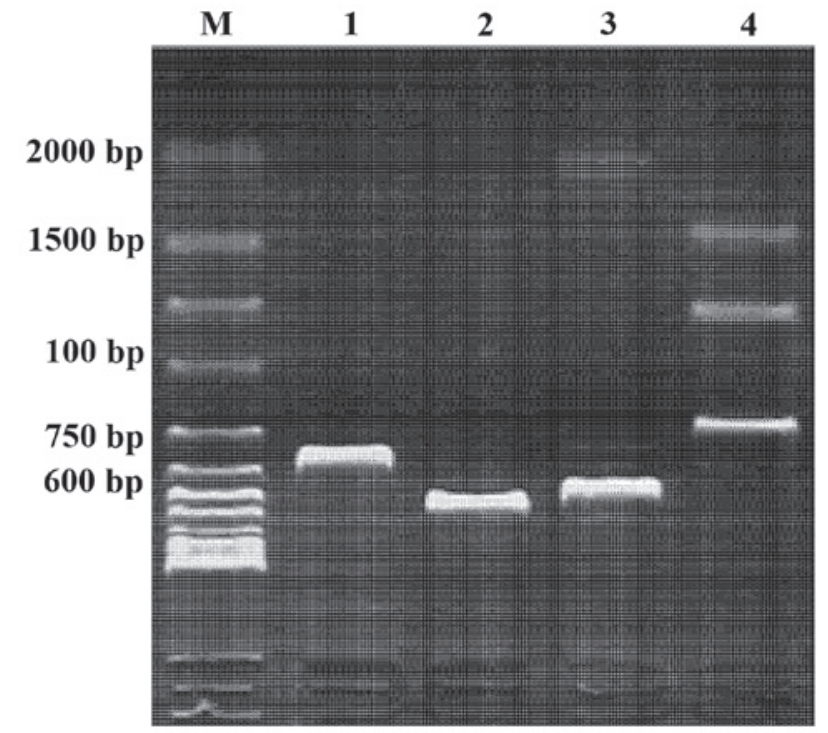

Figure 1. Double digestion and polymerase chain reaction amplification of recombinant plasmids. (M) Standard molecular weight; (1) PCR products; (2) plasmid pcDNA3.1; (3) pcDNA-varicella zoster virus immunoglobulin E (VZV gE) BamHI + EcoR I enzyme digestion products; (4) plasmid pcDNA-VZV gE.

two aliquots were centrifugally washed using $2 \mathrm{ml}$ staining buffer and fixed using $1 \%$ paraformaldehyde in a $500 \mu \mathrm{l} /$ tube. Finally, the expression levels of CD4+ and CD8+ on the cell surface were detected and analyzed using a flow cytometer (Guava easyCyte 6HT-2L; Qzbiotech, Beijing, China) and Cell Quest software (BD Biosciences, Franklin Lakes, NJ, USA).

Lymphocyte proliferation activity as detected by the MTT method. A spleen lymphocyte suspension $(100 \mu \mathrm{l})$ was seeded onto 96-well cell culture plates, 3 wells were prepared for the lymphocytes of each mouse in each group. The blank control well was not inoculated with any cells. The cell culture plate was placed in an incubator containing 5\% $\mathrm{CO} 2$ at $37^{\circ} \mathrm{C}$ for $48 \mathrm{~h}$; and subsequently, each well was supplemented with $20 \mu \mathrm{l}$ MTT (5 mg/ml; MOER Co., Ltd., Hohhot, China) and incubated again as outlined. Following $4 \mathrm{~h}$, the cell culture plate was centrifuged at 5,000 $\mathrm{x} \mathrm{g}$ for $5 \mathrm{~min}$, the cell culture liquid was removed and $100 \mu 1$ hydrochloric acid isopropanol $(0.04 \mathrm{~mol} / \mathrm{l})$ was added to each well. The dark blue granules that were generated were dissolved by mixing fully and a spectrophotometer was used to measure the OD value of each well at $570 \mathrm{~nm}$ with $630 \mathrm{~nm}$ as the reference. The OD value of the pre-tested sample was obtained by subtracting the obtained OD value from the blank culture medium control OD value. The degree of lymphocyte proliferation was expressed as the stimulation index (SI), calculated as follows: $\mathrm{SI}=$ mean OD value of test group/mean OD value of control group. The measured SI values of each group were underwent a statistical analysis using t-test (17).

Statistical analysis. Data are presented as the mean \pm SD of three independent experiments. Statistical analysis was performed using SPSS 15.0 software (SPSS, Inc., Chicago, IL, USA). Mean value comparisons were performed between the groups using a Student's $t$-test. $\mathrm{P}<0.05$ was considered to indicate a statistically significant difference. 
A

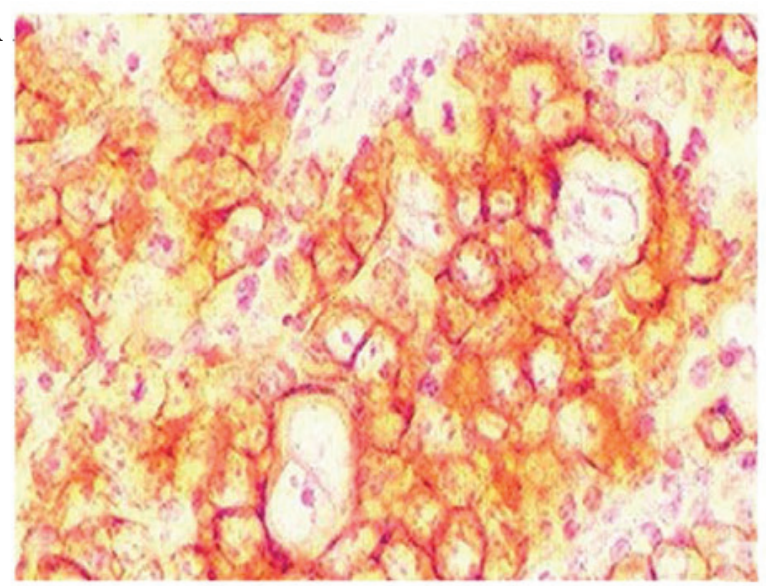

B

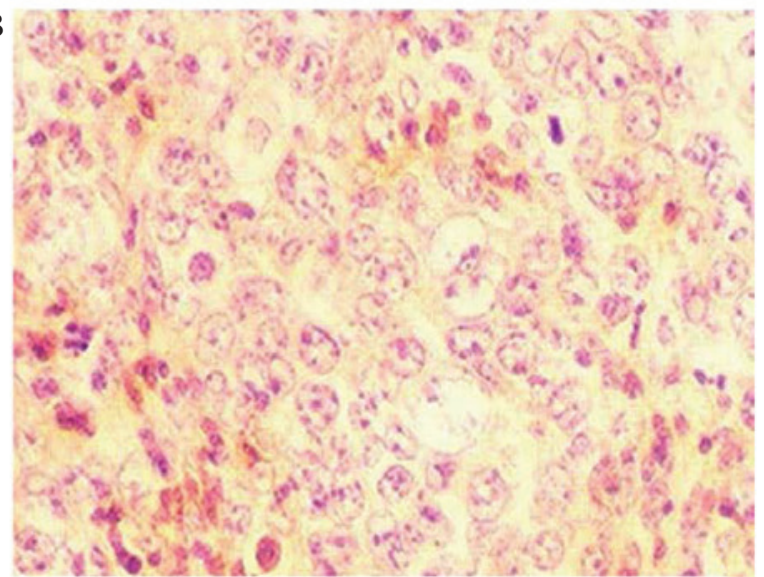

Figure 2. Immunohistochemical staining of COS7 cells transfected with recombinant plasmids (magnification, $\mathrm{x} 200$ ). (A) Immunohistochemical staining of COS7 cells transfected with the pcDNA-VZV gE recombinant vector. Brown particles were detected in the cytoplasm and cell membrane, demonstrating that VZV gE expression is present in the cell and cell membrane. (B) The immunohistochemical staining of COS7 cells transfected with plasmid poDNA3.1.

\section{Results}

Double digestion of recombinant plasmid pcDNA-VZV $g E$. The results of Bam HI and XbaI double digestion and subsequent electrophoresis demonstrated that $\sim 2.7 \mathrm{~kb}$ gE gene fragments were obtained following double digestion of the recombinant plasmid. This result was consistent with the predictions, suggesting that the plasmids were successfully constructed (Fig. 1).

Immunohistochemistry. For the immunohistochemical detection of the instantaneously expressed recombinant protein, the HRP-labeled secondary antibody was added following generation of the pcDNA-VZV gE cells and $\mathrm{gE}$ monoclonal antibody incubation. Following DAB staining, orange particles were detected in the cytoplasm and cell membrane using a microscope. The untransfected cells and those transfected with the pcDNA3.1 null vector did not show staining particles under the same conditions (Fig. 2).

In vivo expression of the pcDNA-VZV gE recombinant plasmid. RT-PCR was conducted using the prepared primers and total RNA from the muscles of mice immunized with pcDNA-VZV gE. The corresponding amplified fragments were consistent with the size of the predicted fragment $(\sim 2.7 \mathrm{~kb})$. Under the same RT-PCR conditions, the total RNA of the mice immunized with blank plasmid pcDNA did not result in expression of the corresponding fragment. This result suggests that the VZV gE recombinant plasmid induces mRNA expression in vivo (Fig. 3).

Detection of the gE antibody in the serum of immunized mice. On days 7, 21 and 35 following immunization, blood samples were collected from the inner canthus of three mice in each group. The serum samples were separated and used to detect specific antibodies. The serum titers of the antigen-specific antibodies were determined using an indirect ELISA. The results demonstrated that the pcDNA-VZV gE group was positive for antigen-specific antibodies following immunization, whereas the pcDNA3.1 and saline groups were negative for $\mathrm{gE}$ antibodies. Therefore, by immunizing mice with the pcDNA-VZV gE plasmid, a humoral

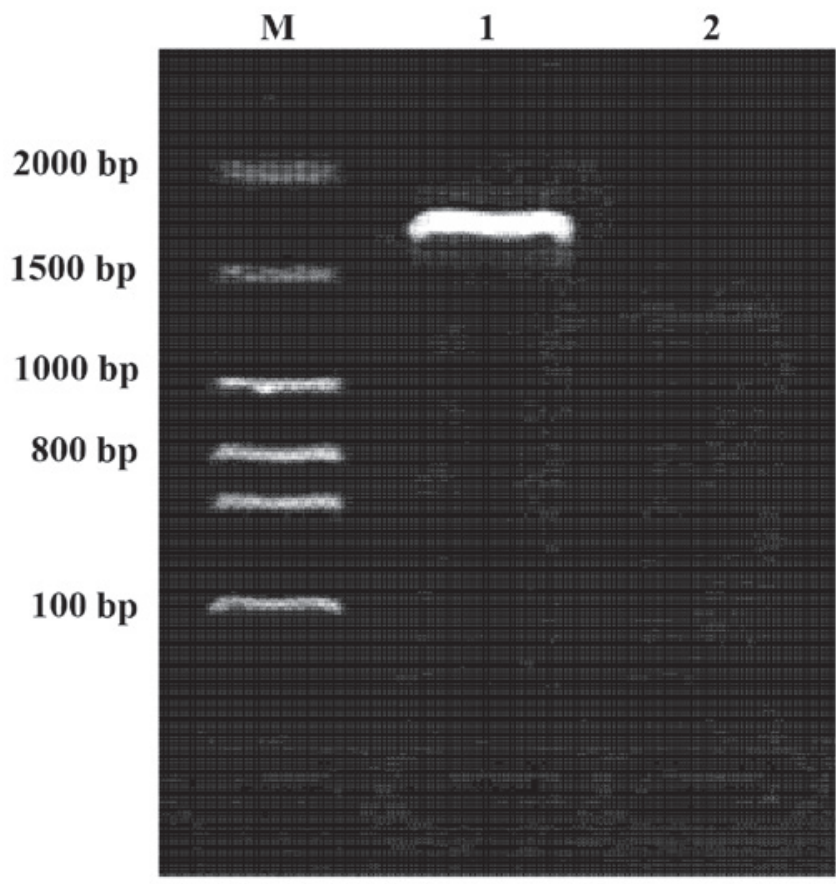

Figure 3. Agarose gel electrophoresis of mouse muscle tissue mRNA following reverse transcription-polymerase chain reaction. $\mathrm{M}$, standard molecular weight; reverse transcription-polymerase chain reaction products of the (lane 1) pcDNA-varicella zoster virus glycoprotein E; and (lane 2) pcDNA 3.1 groups.

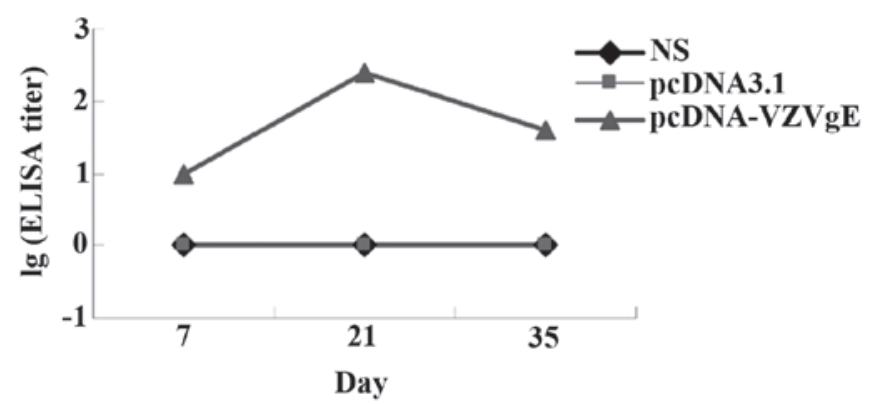

Figure 4. Dynamic changes in antigen specificity in the serum of immunized mice. VZV gE, varicella zoster virus glycoprotein E; NS, normal saline; Ig, immunoglobulin; ELISA, enzyme-linked immunosorbent assay. 
Table I. Titers of antigen specific antibody in the serum of mice following immunization strengthening (IS).

\begin{tabular}{lccc}
\hline Days post-IS & Saline & pcDNA3.1 & pcDNA-VZV gE \\
\hline 7 & 0 & 0 & $1: 32$ \\
21 & 0 & 0 & $1: 256$ \\
35 & 0 & 0 & $1: 64$ \\
\hline
\end{tabular}

VZV gE, varicella zoster virus glycoprotein E.
Table II. Changes in the number of lymphocyte subgroups in the spleen following immunization with the DNA vaccine.

\begin{tabular}{lccc}
\hline Marker & Saline & pcDNA3.1 & pcDNA-VZVgE \\
\hline $\mathrm{CD}^{+}$ & 21.36 & 22.93 & $34.17^{\mathrm{a}}$ \\
$\mathrm{CD}^{+}$ & 10.62 & 11.28 & 12.45 \\
\hline
\end{tabular}

${ }^{\mathrm{a}} \mathrm{P}<0.01$ vs. pcDNA3.1. VZV gE, varicella zoster virus glycoprotein $\mathrm{E}$.

Table III. Spleen lymphocyte proliferation activity following immunization strengthening (IS) in mice.

\begin{tabular}{lcccc}
\hline Days post-IS & Saline & pcDNA3.1 & pcDNA-VZV gE \\
\hline 7 & $0.3244 \pm 0.0136$ & $0.3315 \pm 0.0152$ & $0.5216 \pm 0.0184^{\mathrm{a}}$ & 1.5735 \\
21 & $0.3461 \pm 0.0128$ & $0.3517 \pm 0.0157$ & $0.9554 \pm 0.0162^{\mathrm{a}}$ \\
35 & $0.3647 \pm 0.0137$ & $0.3582 \pm 0.0147$ & $0.8965 \pm 0.0169^{\mathrm{a}}$ & 2.7165 \\
\hline
\end{tabular}

${ }^{\mathrm{a}} \mathrm{P}<0.01$ vs. pcDNA3.1. VZV gE, varicella zoster virus glycoprotein E; SI, stimulation index.

immune response was induced. On day 21 following immunization, the pcDNA-VZV gE group demonstrated the highest antibody titer; however the titer of the antibody had decreased by day 35 (Table I and Fig. 4).

Changes in the number of T cell subgroups in immunized mice. A flow cytometer was used to detect the number of $\mathrm{CD}^{+}$and $\mathrm{CD}^{+}$positive $\mathrm{T}$ cells. The results demonstrated that the total number of T cells in the pcDNA-VZV gE plasmid-immunized group increased, as compared with the control groups (Table II and Fig. 5). In particular, the number of $\mathrm{CD}^{+}{ }^{+}$positive cells significantly increased $(\mathrm{P}<0.01)$. These results suggest that immunization with a recombinant plasmid may effectively increase the number of $\mathrm{T}$ cells and effectively strengthen the immune system of immunized mice.

Detection of spleen lymphocyte proliferation activity in immunized mice. On days 7, 21 and 35 following immunization strengthening, spleen lymphocytes were isolated from three mice in each group under sterile conditions and lymphocyte proliferation activity was determined using the MTT method. The lymphocyte proliferation was significantly greater $(\mathrm{P}<0.01)$ in the pcDNA-VZV gE group, as compared with that of the saline and pcDNA3.1 groups on days 7,21 and 35 following immunization strengthening (Table III and Fig. 6).

\section{Discussion}

Nucleotide vaccines, such as DNA vaccines, contain DNA molecules that are capable of immunizing a host against a pathogen or disease (18). The DNA vaccination process is performed as follows, the exogenous genes are cloned into a eukaryotic expression vector and the recombinant plasmid DNA is injected directly into the animal. These exogenous genes are subsequently expressed in vivo, and the generated antigens activate the immune system, triggering an immune reaction $(19,20)$.

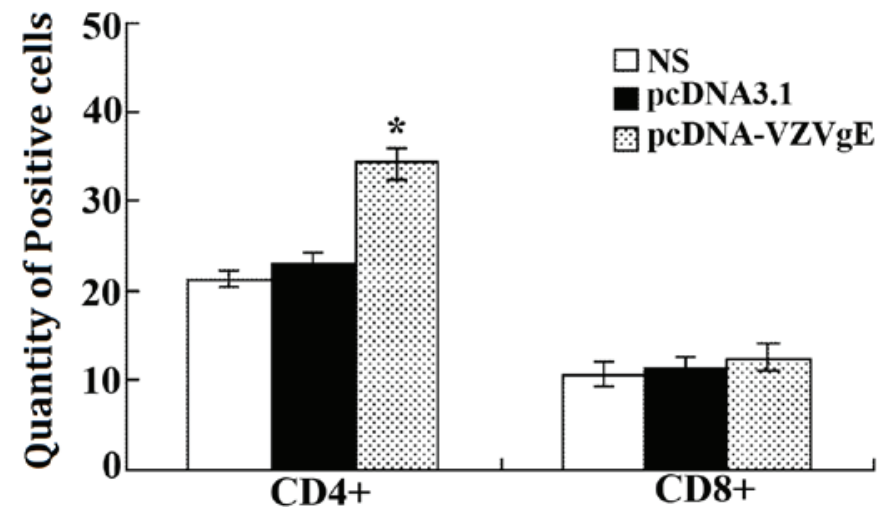

Figure 5. Changes in the number of spleen lymphocyte subgroups following immunization with the DNA vaccine. The number of $\mathrm{CD}^{+}$positive cells significantly increased ( $\mathrm{P}<0.01)$ following immunization, as compared with the NS and pcDNA3.1 groups. VZV gE, varicella zoster virus glycoprotein E. NS, normal saline.

DNA vaccines are different from traditional attenuated pathogen, protein or polypeptide vaccines and, as such, DNA vaccines have particular advantages. DNA vaccines can be simply and effectively produced using molecular biology. Furthermore, the encoded antigen is capable of long-term stable in vivo expression due to transcriptional control by an appropriate promoter, thus inducing antibody and cell immunity. These properties suggest a solid foundation for the widespread application of DNA vaccines $(21,22)$. The biggest limitation of a traditional subunit vaccine is that the antigen cannot be expressed in host cells, therefore cell immunity cannot be induced (23). DNA vaccines are capable of stimulating the synthesis of antigens in the host cells, in a manner similar to the formation of antigens following a pathogenic microorganism infection. The naturally formed antigen is then processed and modified in a normal manner prior to presentation to the immune system, which subsequently stimulates an immune response $(24,25)$. Therefore, DNA 


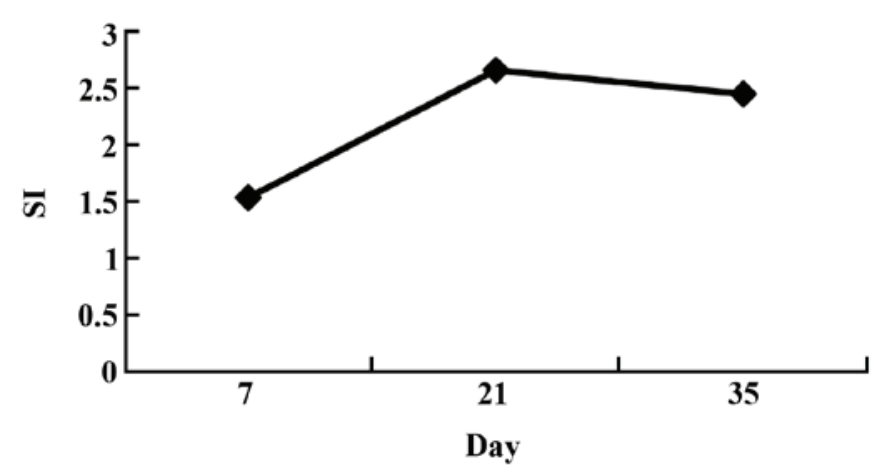

Figure 6. Spleen lymphocyte proliferation activity in immune mice Following immunization strengthening, the lymphocyte proliferation activity of the group immunized with the pcDNA-varicella zoster virus glycoprotein E plasmid was significantly greater than that of the saline and pcDNA3.1 immunized groups $(\mathrm{P}<0.01)$. SI, stimulation index.

vaccines possess the safety of recombinant subunit vaccines and the high efficiency of live attenuated vaccines in inducing a comprehensive immune response (26), and these immunogenic and protective effects have been demonstrated in numerous animal models and preliminary human clinical trials $(27,28)$.

In the present study, a eukaryotic plasmid of the VZV gE antigen, pcDNA-VZV gE, was successfully constructed, transfected into COS7 cells in vitro and stably expressed. This plasmid was subsequently used as a DNA vaccine, and antigen-specific humoral and cellular immune responses were detected on days 7, 14 and 21 following immunization via antigen-specific antibody levels. The results of the present study demonstrated that the VZV gE DNA group presented superior immunogenicity, as compared with the pcDNA3.1 immunization group. Superior immunogenicity was demonstrated in the increased antigen-specific antibody levels generated by the pcDNA-VZV gE DNA vaccine in the immunized mice, the lymphocyte proliferation activity of the immunized mice following in vitro induction culturing. However, by day 35 following immunization strengthening, the specific antibody levels and the cytotoxic activity of lymphocytes in the spleen had decreased in the DNA vaccine-immunized mice. This decrease may be due to an independent replication failure of the plasmid DNA in the mice; therefore, antigen expression levels may gradually decrease with time due to the decomposition of plasmid DNA by host nucleic acid enzymes.

In addition to the detection of immunogenicity through animal experimentation, it is also important to further elucidate the mechanisms by which DNA vaccines immunize hosts in order to enhance the immunogenicity of future DNA vaccines $(29,30)$. For example, intramuscular injection is the predominant method of administration for DNA vaccines. Following inoculation, the corresponding antigen proteins of the DNA vaccine may express in muscle cells; therefore it was initially hypothesized that muscle cells were the predominant cells exerting antigen-presenting function following immunization with a DNA vaccine. However, further research has demonstrated that muscle cells do not express costimulatory molecules, including CD80, also known as B71, and CD86, also known as B7H; therefore, muscle cells do not have a key role in antigen presentation $(31,32)$. Previously, Zhang et al (33) coated gold particles with plasmid DNA and immunized turbot (Scophthalmus maximus) using a gene gun.
By analyzing local draining lymph nodes, Zhang et al demonstrated that the reporter gene and the expression products of the golden particles were predominantly located in dendritic cells; thus demonstrating that professional antigen-presenting cells remained the dominant mechanism of antigen presentation following DNA vaccine immunization. This theory is supported by the majority of research at present (34). Subsequent studies demonstrated that antigen presentation following DNA vaccine immunization was not merely achieved by the passive direct transfection of professional antigen-presenting cells, as it was demonstrated that antigen-presenting cells were capable of uptaking other cells, including muscle cells (35). In this way, these non-professional antigen-presenting cells could be taken up following administration of the DNA vaccine, and the intracellular protein may be released following the physiological apoptosis or pathological necrosis of the cells. That is to say, the antigens expressed following DNA vaccine administration may be presented to CD8+ T cells in combination with major histocompatibility complex (MHC) class I molecules as endogenous antigens. Furthermore, the antigens may be presented to CD4+ T cells by combining with MHC class II molecules as exogenous antigens, resulting in a broader $\mathrm{T}$ cell response $(36,37)$. Therefore, the factors which are capable of promoting the uptake, antigen processing and upregulation of MHC class I and MHC class II molecules' expression levels on antigen presenting cells, including monocytes, macrophages and dendritic cells, are likely to enhance the immunogenicity of DNA vaccines (38).

In the present study, a eukaryotic expression plasmid of the VZV gE protein antigen gene, pcDNA-VZV gE, was constructed and used as a DNA vaccine. This DNA vaccine was used to immunize BALB/c mice and the related indices of cellular and humoral immunity were detected at various time points. The mice that had received the DNA vaccine exhibited increased in vivo antigen-specific antibody levels, spleen lymphocyte proliferation activity following in vitro induction culture and $\mathrm{T}$ cell numbers, as compared with that of the pcDNA3.1 group. Therefore, these results suggested that specific humoral and cellular immune responses were induced in the mice following immunization with the VZV gE gene DNA vaccine constructed in the present study. These results may lay the foundation for further research into a VZV DNA vaccines.

\section{Acknowledgements}

This study was funded by the following projects: The Nature Science Foundation of Inner Mongolia Autonomous Region (2013MS1224); Science and Technology Innovation Fund of Provincial Department of Finance, Inner Mongolia Autonomous Region; Collaborative Innovation Project of Mogolian Medicine, Inner Mongolia Autonomous Region; Technology Reserve Project of Provincial Department of Science and Technology, Inner Mongolia Autonomous Region.

\section{References}

1. Schub D, Janssen E, Leyking S, Sester U, Assmann G, Hennes P, Smola S, Vogt T, Rohrer T, Sester M and Schmidt T: Altered phenotype and functionality of varicella zoster virus-specific cellular immunity in individuals with active infection. J Infect Dis 211: 600-612, 2015. 
2. Kim YH,Hwang JY,Lee KM, Choi JH,Lee TY, Choi JS and Park HS Seroepidemiologic survey of varicella-zoster virus in korean adults using glycoprotein enzyme immuno assay and fluorescent antibody to membrane antigen test. Ann Dermatol 23: 39-43, 2011.

3. Suenaga T, Matsumoto M, Arisawa F, Kohyama M, Hirayasu K, Mori $\mathrm{Y}$ and Arase $\mathrm{H}$ : Sialic acids on varicella-zoster virus glycoprotein B are required for cell-cell fusion. J Biol Chem 290: 19833-19843, 2015.

4. Dendouga N, Fochesato M, Lockman L, Mossman S and Giannini SL: Cell-mediated immune responses to a varicella-zoster virus glycoprotein $E$ vaccine using both a TLR agonist and QS21 in mice. Vaccine 30: 3126-3135, 2012.

5. Grahn A, Studahl M, Nilsson S, Thomsson E, Bäckström M and Bergström T: Varicella-zoster virus (VZV) glycoprotein E is a serological antigen for detection of intrathecal antibodies to VZV in central nervous system infections, without cross-reaction to herpes simplex virus 1. Clin Vaccine Immunol 18: 1336-1342, 2011.

6. Thomsson E, Persson L, Grahn A, Snäll J, Ekblad M, Brunhage E, Svensson F, Jern C, Hansson GC, Bäckström M and Bergström T: Recombinant glycoprotein E produced in mammalian cells in large-scale as an antigen for varicella-zoster-virus serology. J Virol Methods 175: 53-59, 2011.

7. Oliver SL, Sommer MH, Reichelt M, Rajamani J, Vlaycheva-Beisheim L, Stamatis S, Cheng J, Jones C, Zehnder J and Arvin AM: Mutagenesis of varicella-zoster virus glycoprotein I (gI) identifies a cysteine residue critical for $\mathrm{gE} / \mathrm{gI}$ heterodimer formation, gI structure and virulence in skin cells. J Virol 85: 4095-4110, 2011.

8. Zerboni L, Berarducci B, Rajamani J, Jones CD, Zehnder JL and Arvin A: Varicella-zoster virus glycoprotein $\mathrm{E}$ is a critical determinant of virulence in the SCID mouse-human model of neuropathogenesis. J Virol 85: 98-111, 2011.

9. Permyakova NV, Zagorskaya AA, Belavin PA, Uvarova EA, Nosareva OV, Nesterov AE, Novikovskaya AA, Zav'yalov EL, Moshkin MP and Deineko EV: Transgenic carrot expressing fusion protein comprising $M$. tuberculosis antigens induces immune response in mice. Biomed Res Int 2015: 417565, 2015.

10. Berarducci B, Rajamani J, Zerboni L, Che X, Sommer M and Arvin AM: Functions of the unique N-terminal region of glycoprotein $\mathrm{E}$ in the pathogenesis of varicella-zoster virus infection. Proc Natl Acad Sci USA 107: 282-287, 2010.

11. Ali MA, Li Q, Fischer ER and Cohen JI: The insulin degrading enzyme binding domain of varicella-zoster virus (VZV) glycoprotein E is important for cell-to-cell spread and VZV infectivity, while a glycoprotein I binding domain is essential for infection. Virology 386: 270-279, 2009 .

12. Sauerbrei A, Wiesener N, Zell R and Wutzler P: Sequence analysis of the glycoprotein $\mathrm{E}$ gene of varicella-zoster virus strains of clades 1, 3 and 5. Arch Virol 156: 505-509, 2011.

13. Wang M, Tang JW, Song B, Wang B, Zhang J, Wei YY, Zhang YH and Liu JW: Construction and identification of recombinant eukaryotic plasmid pcDNA3.1(+)-ECH1. Zhong Hua Bing Li Xue Za Zhi 40: 334-335, 2011 (In Chinese).

14. Zhang Y, Chang S, Sun J, Zhu S, Pu C, Li Y, Zhu Y, Wang Z and Xu RX: Targeted microbubbles for ultrasound mediated short hairpin RNA plasmid transfection to inhibit survivin gene expression and induce apoptosis of ovarian cancer A2780/DDP Cells. Mol Pharm 12: 3137-3145, 2015.

15. Liu JC, Lengner CJ, Gaur T, Lou Y, Hussain S, Jones MD, Borodic B, Colby JL, Steinman HA, van Wijnen AJ, et al: Runx2 protein expression utilizes the Runx 2 P1 promoter to establish osteoprogenitor cell number for normal bone formation. J Biol Chem 286: 30057-30070, 2011.

16. Laderman EI, Whitworth E, Dumaual E, Jones M, Hudak A, Hogrefe W, Carney J and Groen J: Rapid, sensitive and specific lateral-flow immunochromatographic point-of-care device for detection of herpes simplex virus type 2-specific immunoglobulin $\mathrm{G}$ antibodies in serum and whole blood. Clin Vaccine Immunol 15: 159-163, 2008.

17. Shipkova M and Wieland E: Surface markers of lymphocyte activation and markers of cell proliferation. Clin Chim Acta 413: $1338-1349,2012$

18. Im EJ,Borducchi EN, Provine NM, McNally AG, Li S, Frankel FR and Barouch DH: An attenuated Listeria monocytogenes vector primes more potent simian immunodeficiency virus-specific mucosal immunity than DNA vaccines in mice. J Virol 87 4751-4755, 2013

19. Chesnut G, McClain D and Galeckas K: Varicella-zoster virus in children immunized with the varicella vaccine. Cutis 90 : 114-116, 2012.
20. Ghanem A, Healey R and Adly FG: Current trends in separation of plasmid DNA vaccines: A review. Anal Chim Acta 760: 1-15, 2013

21. Storlie J, Maresova L, Jackson W and Grose C: Comparative analyses of the 9 glycoprotein genes found in wild-type and vaccine strains of varicella-zoster virus. J Infect Dis 197 (Suppl 2): S49-S53, 2008.

22. Berarducci B, Rajamani J, Reichelt M, Sommer M, Zerboni L and Arvin AM: Deletion of the first cysteine-rich region of the varicella-zoster virus glycoprotein $\mathrm{E}$ ectodomain abolishes the $\mathrm{gE}$ and gI interaction and differentially affects cell-cell spread and viral entry. J Virol 83: 228-240, 2009.

23. Polack FP, Lydy SL, Lee SH, Rota PA, Bellini WJ, Adams RJ, Robinson HL and Griffin DE: Poor immune responses of newborn rhesus macaques to measles virus DNA vaccines expressing the hemagglutinin and fusion glycoproteins. Clin Vaccine Immunol 20: 205-210, 2013.

24. Meng M, He S, Zhao G, Bai Y, Zhou H, Cong H, Lu G, Zhao Q and Zhu XQ: Evaluation of protective immune responses induced by DNA vaccines encoding Toxoplasma gondii surface antigen 1 (SAG1) and $14-3-3$ protein in BALB/c mice. Parasit Vectors 5: 273, 2012.

25. Galli V, Simionatto S, Marchioro SB, Fisch A, Gomes CK, Conceição FR and Dellagostin OA: Immunisation of mice with Mycoplasma hyopneumoniae antigens P37, P42, P46 and P95 delivered as recombinant subunit or DNA vaccines. Vaccine 31: 135-140, 2012.

26. Herrada AA, Rojas-Colonelli N, González-Figueroa P, Roco J, Oyarce C, Ligtenberg MA and Lladser A: Harnessing DNA-induced immune responses for improving cancer vaccines. Hum Vaccin Immunother 8: 1682-1693, 2012.

27. Fredriksen AB, Sandlie I and Bogen B: Targeted DNA vaccines for enhanced induction of idiotype-specific B and T cells. Front Oncol 2: 154, 2012.

28. Yu YZ, Li N, Ma Y, Wang S, Yu WY and Sun ZW: Three types of human $\mathrm{CpG}$ motifs differentially modulate and augment immunogenicity of nonviral and viral replicon DNA vaccines as built-in adjuvants. Eur J Immunol 43: 228-239, 2013.

29. Martinez-Lopez A, Encinas P, García-Valtanen P, Gomez-Casado E, Coll JM and Estepa A: Improving the safety of viral DNA vaccines: Development of vectors containing both 5 ' and 3' homologous regulatory sequences from non-viral origin. Appl Microbiol Biotechnol 97: 3007-3016, 2013.

30. Cai MS, Deng SX and Li ML: Comparison of the immune responses in BALB/c mice following immunization with DNA-based and live attenuated vaccines delivered via different routes. Vaccine 31: 1353-1356, 2013.

31. Li L, Saade F and Petrovsky N: The future of human DNA vaccines. J Biotechnol 162: 171-182, 2012.

32. Hartikka J, Bozoukova V, Morrow J, Rusalov D, Shlapobersky M, Wei Q, Boutsaboualoy S, Ye M, Wloch MK, Doukas J, et al: Preclinical evaluation of the immunogenicity and safety of plasmid DNA-based prophylactic vaccines for human cytomegalovirus. Hum Vaccin Immunother 8: 1595-1606, 2012.

33. Zhang M, Hu YH, Xiao ZZ, Sun Y and Sun L: Construction and analysis of experimental DNA vaccines against megalocytivirus. Fish Shellfish Immunol 33: 1192-1198, 2012.

34. Jiang DB, Sun YJ, Cheng LF, Zhang GF, Dong C, Jin BQ, Song CJ, Ma Y, Zhang FL and Yang K: Construction and evaluation of DNA vaccine encoding Hantavirus glycoprotein $\mathrm{N}$-terminal fused with lysosome-associated membrane protein. Vaccine 33: 3367-3376, 2015.

35. Zhai Y, Zhou Y, Li X and Feng G: Immune-enhancing effect of nano-DNA vaccine encoding a gene of the prME protein of Japanese encephalitis virus and BALB/c mouse granulocyte-macrophage colony-stimulating factor. Mol Med Rep 12: 199-209, 2015.

36. Malavige GN, Jones L, Black AP and Ogg GS: Varicella zoster virus glycoprotein E-specific CD4+ T cells show evidence of recent activation and effector differentiation, consistent with frequent exposure to replicative cycle antigens in healthy immune donors. Clin Exp Immunol 152: 522-531, 2008.

37. Schmidt-Chanasit J, Bleymehl K, Schäd SG, Gross G, Ulrich RG and Doerr HW: Novel varicella-zoster virus glycoprotein $\mathrm{E}$ gene mutations associated with genotypes A and D. J Clin Microbiol 46: 325-327, 2008

38. Connolly RJ, Chapman T, Hoff AM, Kutzler MA, Jaroszeski MJ and Ugen KE: Non-contact helium-based plasma for delivery of DNA vaccines: Enhancement of humoral and cellular immune responses. Hum Vaccin Immunother 8: 1729-1733, 2012. 